\title{
PHYSICAL THERAPY OPTIONS FOR THE TREATMENT AND PREVENTION OF OSTEOPOROSIS
}

\author{
Mihaylova Mariyana, \\ PhD, Associate Professor, Faculty of Public health, Department of Physiotherapy, rehabilitation, \\ thalassotherapy and occupational diseases, Medical University of Varna, Bulgaria, \\ ORCID ID: https://orcid.org/0000-0001-5130-9743
}

DOI: https://doi.org/10.31435/rsglobal_ws/30062020/7109

\section{ARTICLE INFO}

Received: 13 April 2020

Accepted: 15 June 2020

Published: 30 June 2020

\section{KEYWORDS}

osteoporosis, physical therapy, prevention.

\begin{abstract}
There's a global trend observed in the recent decades of increasing number of people suffering from osteoporosis.

Alarming is the fact that osteoporotic fractures are one of the main causes of morbidity and mortality, especially in developed countries.

The possibilities offered by physical therapy for the prevention and treatment of osteoporosis still do not have the necessary popularity among the healthcare professionals and the affected persons.

The purpose of this review is to look at the options for treating and preventing osteoporosis through physical therapy.

The timely and professionally conducted rehabilitation not only improves the general physical condition of affected persons, but also contributes to an increase in the psycho-emotional tone, quality of life and independence in everyday life, which are one of the important priorities of any treatment.
\end{abstract}

Citation: Mihaylova Mariyana. (2020) Physical Therapy Options for the Treatment and Prevention of Osteoporosis. World Science. 6(58), Vol.2. doi: 10.31435/rsglobal_ws/30062020/7109

Copyright: (C) 2020 Mihaylova Mariyana. This is an open-access article distributed under the terms of the Creative Commons Attribution License (CC BY). The use, distribution or reproduction in other forums is permitted, provided the original author(s) or licensor are credited and that the original publication in this journal is cited, in accordance with accepted academic practice. No use, distribution or reproduction is permitted which does not comply with these terms.

Introduction. There's a global trend observed in the recent decades of increasing number of people suffering from osteoporosis. The illness affects and makes suffer not only the elderly, but also a very large proportion of people of working age, believed to be the result of the modern lifestyle. Alarming is the fact that osteoporotic fractures are one of the main causes of morbidity and mortality, especially in developed countries. This makes the issues of prevention and treatment of osteoporosis particularly relevant. On one hand, because of the increase in the number of people affected and on the other because of the high social and economic cost that society pays. In fact, the diagnosis is clarified too late due to a lack of clinical manifestations at the onset of the disease, and this leads to a prolongation and further costs of treatment, as well as a deterioration in the quality of life of many people.

The possibilities offered by physical therapy for the prevention and treatment of osteoporosis still do not have the necessary popularity among the healthcare professionals and the affected persons.

Risk factors for developing osteoporosis. In order to conduct a proper prophylaxis of the osteoporosis is required solid understanding of its risk factors as well as ways to treat them. A large group of them, such as age, ethnicity, gender, genetic factors, a history of past fractures, can not be changed. $[15,18,30]$. It's especially important to consider risk factors that can be changed and controlled through competent intervention by physicians, namely physical activity, nutrition, body mass, harmful habits, acute and chronic psycho-emotional stress.

One such important factor is the need for higher levels of physical activity during the period of growth of the body to achieve better mature bone mineral density parameters is justified [5]. Medical research shows that physical exercises in puberty contribute to the development of healthy bones with 
better physical characteristics in both sexes. According to Wolff's widely known law regarding the effects of mechanical stress on bones and the existence of a direct relationship between the level of mechanical bone loading and the processes of formation and remodeling. This so important mechanical stimulus that bones need may be as the result of muscle contraction or exercising of axial pressure on them. In the opposite case where the supporting function of the skeleton decreases and there is no pressure on bones or stretching of the muscles, osteoporosis starts to develop [2]. Medical research has shown that immobilization results in an accelerated reduction in muscle and bone mass $[24,25]$. In the experiments, it was found that osteocytes found in the mineralized bone matrix respond to intracellular fluid movements occurring in a mechanical signal and by intercellular interaction stimulate proliferation of osteoblasts and rapid increase in alkaline phosphatase (bone formation marker) [26]. Mechanical load, respectively, physical activity is a key factor in preventing bone mass reduction. Optimal physical activity is a prerequisite for reducing bone loss during pre-menopause and reducing bone density loss associated with aging.

The role of proper nutrition for bone health, both in growth and adulthood is unquestionable. Emphasis is put on the need for adequate calcium intake to reduce the risk of fractures and the mandatory presence of sufficient vitamin $\mathrm{D}$ intake which helps calcium absorption of the body and the normal course of metabolic processes in the bone tissue $[6,12]$ It's important to reduce the intake of certain substances such as ethanol, caffeine, etc. has been grounded, as they are directly related to increased calcium excretion and their increased use may have a negative effect on bone tissue $[20,16]$.

Unfortunately, chronic psychological stress also takes part in reducing bone mass and deteriorating bone quality. It is believed that the effect is realized by activating the hypothalamuspituitary-adrenal-axis sympathetic nervous system [3]

Harmful habits have negative impact on bone metabolism as well. Evidence has been presented about the high doses of alcohol that have a direct anti-osteoblastic effect. Indicated are the harmful effects that smoking has on bone health through a change in hormone metabolism, a reduction in body weight, vitamin D levels, and calcium absorption. Disturbed microcirculation and increased oxidative stress as a result of smoking impair the processes of bone resorption and contribute to the formation of lower bone mass $[9,14]$.

Modern tendencies in osteoporosis treatment. The modern complex method for effectively treating osteoporosis and its complications includes drug treatment and conservative non-medication therapy.

However, conservative non-medication treatment of osteoporosis is still an insufficiently absorbed resource.

The possibilities of physical therapy, especially in the early stages of bone loss between 40 and 50 years of age, as well as in the stage of developed osteopenia, to affect bone remodeling, which unfortunately still have no and have not been studied sufficiently.

The services of a specialist in physical and rehabilitation medicine are sought after in an already manifested pain syndrome due to severe osteoporosis or after osteoporotic fracture. Literature data suggest that the earlier the prevention begins, the greater the possibilities for prevention of the disease.

The aims and objectives of physical therapy in osteoporosis are formulated and focused on stimulation of the processes of bone building and suppression of bone resorption. Important tasks include targeted events aimed at increasing muscle mass and strength, strengthening musculoskeletal system, increasing the motor volume of the peripheral joints, as well as posture correction, stabilization of gait and balance to reduce fracture risk. Selected physical factors aim to stimulate regenerative and restorative processes after osteoporotic fractures, suppress pain syndrome and potentiate the action of anti-osteoporotic drugs. These complex events help to improve the quality of life of patients with OP.

Kinesitherapy. The potential benefits of different kinesitherapy agents for the influence of bone metabolism are presented. Emphasis is put on the means of healing physical exercise, namely the physical exercises with the greatest effect on bone health. As a mandatory element of a kinesitherapeutic program, balance and coordination training exercises, which are aimed at training the vestibular apparatus, body balance and coordination of movements have also been mentioned [21]. The ability to maintain body balance decreases with age, resulting in an increased risk of falling in people over 65 years of age. Coordination and balance exercises have proven effectiveness as a measure to prevent falls $[11,27]$. They are especially important for mature women, especially those who have difficulty walking and lack of dexterity in performing complex coordination movements, 
and are therefore exposed to the greatest fracture risk. Multiple publication analyses proves that systemic Tai Chi workouts have an extremely favorable effect on balance and selected motor functions in the elderly [22].The advantages of the Tai Chi method in the reviewed pathology are in terms of improved concentration and body control, improved balance and posture, good muscle tone, increased volume of movement, and safety when used by adults [8]. Pilates and Yoga methods has been considered. They poses the ability to increase the mobility of the musculoskeletal system, to suppress pain sensations, and also to positively influence the patient's bone strength and psycho-emotional tone. Increased bone mineral density is also reported with their systematic application [17,19].

Preformed physical factors. The preformed physical factors could also be applied, both for prevention and treatment of OP and its complications, have been examined. With respect to their indications and their clinical efficacy, much experience has been gained in this pathology. They are successfully applied as an element of a complex rehabilitation program in order to potentiate the effects of drug therapy and kinesitherapy, namely to enhance the trophic, analgesic, muscle relaxing or myostimulating effect [28,29]. The extreme role of the magnetic field on bone metabolism is highlighted. It influences local blood flow activation, microcirculation and transcapillary exchange is improved, blood supply to the organs and tissues is increased, inflammation processes are reduced. Stimulated proliferative processes in cellular elements of bone tissue in magnetotherapy contribute to a faster consolidation of fractures. The prominent trophic and bone-modeling effect of low-frequency magnetic fields allows to actively influence the mineralization processes of bone tissue. Ultrasound therapy, electrophoresis and interference currents also have good potential for stimulating bone metabolism. Ultrasound can be considered as a physical catalyst for a number of physico-chemical and biophysical processes in the body. Based on this, it has a stimulating effect on cellular functions as a whole, on intracellular regeneration, improves blood circulation, increases oxygen uptake by tissues, has an analgesic effect, improves overall functional status of bone-muscular system [4]. Ultraviolet rays stimulate the natural synthesis of vitamin D3, which is particularly vital for the calcium-phosphorus exchange and for balancing the processes of bone formation and resorption [10]. The use of UV rays may be in the form of both heliotherapy - natural exposure to sunlight or in the form of exposure to quartz lamps or solariums. A dosed and rational application of UV radiation leads to positive effects on overall health of people and in particular contributes to the maintenance of bone health.

Natural and alternative physical factors. Some natural physical factors - mineral waters and peloids could also be used to stimulate and maintain a positive bone balance in the body in order to reduce the physiologically age determined bone loss. Of interest are some of the newer methods presented, which are still subject of study, such as ozone therapy, hyperbaric oxygenation, which can be apploed to stimulate the accumulation of bone mass [1,13]. Acupuncture and moxa therapy are possible alternative in this pathology, as there have already been reported good results in their application in terms of pain suppression, normalization of the hormone background in menopausal women and limiting bone resorption [7,23].

Modern complex rehabilitation approach and individual rehabilitation plan. The modern complex rehabilitation approach in the treatment of osteoporosis requires close collaboration between different specialists is the earliest possible accurate diagnosis and as soon as possible undergoing a complex treatment in the shortest possible terms, including drug therapy and physiotherapy tailored to the stage of the disease.

The basic principle is setting up a rehabilitation program, namely an individual approach to each single patient. Rehabilitation events should be optimal for the clinical form and stage of their disease, aimed at maximizing the reduction of pain and sensory disorders (if any), improving postural reflexes, restoring normal spinal biomechanics, increasing muscle strength and improving the quality of life of patients. A proper and timely therapeutic approach is crucial for the complete recovery of patients and the prevention of severe complications. The contribution of physical means to maintaining a more favorable psycho-emotional tone of patients, which in this pathology is not to be neglected is also emphasized. Delaying adequate rehabilitation is a cause of a significant cost spending for subsequent rehabilitation events and a prolongation of the rehabilitation period.

The success of physical therapy depends on both a precisely drawn rehabilitation program and on the cooperation and interest of the respective patient. Collaboration between physician and patient is a must.

Conclusions. Global trends of increase in the number of people affected by the disease are an alarming signal to the medical community. It's important to focus on the development of prevention 
programs targeting the teenage group because the foundations of a healthy skeleton are laid in a period of strong growth and childhood investment is the basis for good bone health in the adult age.

The modern complex therapeutical approach to osteoporosis requires the intervention of a team of specialists from different fields of medicine, among which specialists in physical and rehabilitation medicine have their deserved place. This is argumented by the wide variety of physical methods, which have multiple possibilities both in the field of prevention and as a healing tool. The action of physical factors in osteoporosis and its complications is multi-directional. On the one hand, they are related to maintaining and preserving the maximum age-based motor function and training in a correct motor stereotype, on the other hand they maintain the homeostasis in the body or, in other words, having a regulatory effect. Moreover, physical factors have an expressed trophic effect on bone formation processes and contribute to maintaining and increasing muscle mass, and the analgesic effect is undoubted. The timely and professionally conducted rehabilitation not only improves the general physical condition of affected persons, but also contributes to an increase in the psychoemotional tone, quality of life and independence in everyday life, which are one of the important priorities of any treatment.

\section{REFERENCES}

1. Гюльназарова С. В., Кучиев А. Ю., Трифонова Е. Б., Кудрявцева И. П. 2015. Гипербарическая оксигенация: теория и практика коррекции посттравматического остеопороза. Научное обозрение. Реферативный журнал № 1, с. 24-24.

2. Икономова, К., et al. 2012. Клетъчна и молекулна структура на костта. Лабораторни показатели за изследване, бр. 3, 20-27

3. Azuma K., Adachi Y., Hayashi H., Kubo K.Y. 2015. Chronic Psychological Stress as a Risk Factor of Osteoporosis. J UOEH. 37(4): 245-53.

4. Bayat M.Z., et al. 2017. „Comparison of the in vitro effects of low-level laser therapy and low-intensity pulsed ultrasound therapy on bony cells and stem cells." Progress in biophysics and molecular biology

5. Bielemann R.M., Martinez-Mesa J., Gigante D.P. 2013. «Physical activity during life course and bone mass: a systematic review of methods and findings from cohort studies with young adults» BMC musculoskeletal disorders 14.1, 77.

6. Bikle D.D., 2012. «Vitamin D and bone». Current osteoporosis reports 10.2, 151-15

7. Cai G.W., et al. 2014. «Clinical research on warm acupuncture therapy for pain in postmenopausal osteoporosis». Zhongguo zhen jiu = Chinese acupuncture \& moxibustion 34.1: 25-27.

8. Chow T.H., Lee B.Y., Ang ABF, Cheung VYK, Ho MMC, Takemura S.J. 2018. Orthop Translat The effect of Chinese martial arts Tai Chi Chuan on prevention of osteoporosis:A systematic review. 12: 74-84.

9. Cusano N.E. 2015. «Skeletal effects of smoking». Current osteoporosis reports 13.5:302-309.

10. Grotting ÅRL. 2016. Geographical variation in hip fracture incidence in a Nordic Population (Sweden): a GIS study exploring the covariation between UV radiation and osteoporosisat different latitudes. MS thesis. Norwegian University of Life Sciences, Ås.

11. Halvarsson, Alexandra, et al. 2016. „Long-term effects of a progressive and specific balance-training programme with multi-task exercises for older adults with osteoporosis:a randomized controlled study." Clinical rehabilitation 30.11: 1049-1059.

12. Heaney R.P. 2009. Dairy and bone health. J Am Coll Nutr; 28 Suppl 1: 82S-90S.

13. Ibrahim G.D., Davul S., Gokce H., et al. 2017. Effects of Gaseous Ozone Treatment on Bone Regeneration in Femoral Defect Model in Rats. Journal of Hard Tissue Biology 26: 7-12.

14. Kanis J.A., Johnell O., Oden A., Johansson H., De Laet C., Eisman J.A., et al. 2015. Smoking and fracture risk: a meta-analysis Cusano, Natalie E. ,Skeletal effects of smoking.” Current osteoporosis reports 13.5: 302-309.

15. Katsimbri P. 2017. „The biology of normal bone remodelling.” European journal of cancer care 26.6: e12740.

16. Korkor A.B., Eastwood D., Bretzmann C. 2009. Effects of gender, alcohol, smoking, and dairy consumption on bone mass in Wisconsin adolescents. WMJ 108: 181-188.

17. Küçükçakır, N., L. Altan, and N. Korkmaz. 2013. „Effects of Pilates exercises on pain,functional status and quality of life in women with postmenopausal osteoporosis."Journal of bodywork and movement therapies 17.2: 204-211.

18. Loud K.J., Micheli L.J., Bristol S., Austin S.B., Gordon C.M. 2007. Family history predicts stress fracture in active female adolescents. Pediatrics 120:e364-e372.

19. Lu Y.H., et al. 2016. „Twelve-minute daily yoga regimen reverses osteoporotic bone loss.” Topics in geriatric rehabilitation 32.2: 81 .

20. Massey K.L., Sutton A.L.R. 2004. „Acute caffeine effects on urine composition and calcium kidney stone risk in calcium stone formers." The Journal of urology 172.2 :555-558. 
21. Mihaylova M. 2018. The contribution of physical exercises to treatment and prophylaxis of osteoporosis. International Scientific and Practical Conference „WORLD SCIENCE” №4(3), Vol. 5, 31-34.

22. Pan Z., Su X., Fang Q., et al. 2018. The Effects of Tai Chi Intervention on Healthy Elderly by Means of Neuroimaging and EEG: A Systematic Review. Front Aging Neurosci;10:110.

23. Pan H., et al. 2018. „The Effectiveness of Acupuncture for Osteoporosis: A Systematic Review and MetaAnalysis." The American journal of Chinese medicine $46.03: 489-513$.

24. Parry, S.M., Puthucheary, Z.A. 2015. „The impact of extended bed rest on the musculoskeletal system in the critical care environment." Extreme physiology \& medicine 4.1:16.

25. Preiser J.C., et al. 2010. Effects of bedrest on muscle metabolism. Pratic Anesth Reanim.14(2): 80-84.

26. Riddle R.C., Donahue H.J. 2009. From streaming-potentials to shear stress: 25 years of bone cell mechanotransduction. J Orthop Res. 27: 143-149.

27. Vieira E.R., et al. 2016. „Prevention of falls in older people living in the community.” bmj 353.1: 1419

28. Wang R., et al. 2016. „Effects of electromagnetic fields on osteoporosis: A systematic literature review.” Electromagnetic biology and medicine 35.4: 384-390.

29. Yuan J., Xin F., Jiang W. 2018. „Underlying Signaling Pathways and Therapeutic Applications of Pulsed Electromagnetic Fields in Bone Repair." Cellular Physiology and Biochemistry 46.4: 1581-1594.

30. Zengin A., Prentice D., Ward K.A. 2015. „Ethnic differences in bone health.” Frontiers in endocrinology 6: 24. 